\title{
Space Thermoacoustic Radio-Isotopic Power System: SpaceTRIPS
}

\author{
Antoine Alemany, Maurice Francois ${ }^{1 *}$, Kees de Blok², Roux Jean Pierre, - Poli Gerard ${ }^{3}$, \\ Eleonnora Zeminiani - Enrico Gaia ${ }^{4}$, Phillipe Jeantet - Emmanuel Roy - Christian Chillet ${ }^{5}$, \\ Janis Freiberg, - Raimonds Nikoluškins ${ }^{6}$, Gunter Gerbeth - Sven Eckert ${ }^{7}$ \\ ${ }^{1}$ Company HEKYOM Fr, ${ }^{2}$ Company ASTER Ne, ${ }^{3}$ Company AREVA T.A Fr., ${ }^{4}$ Company Thales Alenia Space It, ${ }^{5}$ CNRS \\ Fr, ${ }^{6}$ Institute of Physics of the University of Latvia IPUL Lv, ${ }^{7}$ Helmholtz-Zentrum Dresden-Rossendorf HZDR De. \\ * Corresponding author's e-mail: Maurice.francois@hekyom.com
}

\section{Objective}

The project relates to an advanced thermal to electric conversion for radio-isotopic power systems (RPS). Indeed RPSs are a key for space exploration as the solar power is very low in deep space, notably in Jupiter orbit and beyond. These systems will be also useful for Mars exploration, where solar power is subject to nights and dust storms. Thus, Europe aims to get its independence for such missions, and ESA have initiated development of RPS. If thermoelectricity fits well with small RPS (e.g.20We), for 100We range, high efficiency conversion is desirable. Indeed this leads to save between $2 / 3$ up to $3 / 4$ of the radioisotope mass. This is of real importance in term of cost and safety. Stirling converters under development in USA have low reliability due to pistons (sensitive to launch vibrations and shocks, subject to wear). Thermoacoustic (TAC), coupled with magneto hydrodynamic (MHD) generator is innovating technology free of moving parts. Unfortunately, the Technological Readiness Level is low and the priority is given to Stirling in ESA's programme, even if ESA has supported the first studies of TAC-MHD systems. This project is complementary with ESA's approach. So, the objective of this Project is to raise the TRL of this technology from 2 to 3-4 and show that this option is viable for European RPSs. The approach is based on 3 axes: Theoretical modeling, which has been already developed but needs to be validated, Experimentation of a thermo acoustic engine coupled with a MHD generator, Design of the space RPS, equipped with this conversion system, to check if the technology is suitable for space mission. The targets are: $1 /$ to validate the process efficiency (close to $20 \%$ or above), 2 / to justify the compatibility of the technology with space missions,

\section{Methodological approach and results}

The project is based on numerical calculation, design construction and test of a thermoacoustic loop coupled with an MHD generator using liquid sodium (cold source temperature above 400K), to convert mechanical energy furnished by the thermoacoustic loop in electricity. The TAC loop is of toroidal shape and is used in push pull action using two 'heat driven' thermoacoustic engine. In the facility the hot sources will be electrical resistances able to furnish $1400 \mathrm{w}$. the temperature at the hot source can reach $1200 \mathrm{~K}$. The other characteristic of this loop is given in Table 1.

\begin{tabular}{|l|l|l|}
\hline \multirow{4}{*}{ Pressure values } & Heat exchangers & $40 \pm 0.6 \mathrm{bars}$ \\
\cline { 2 - 3 } & Three way connections & $40 \pm 1 \mathrm{bars}$ \\
\cline { 2 - 3 } & MHD Adapters & $40 \pm 7 \mathrm{bars}$ \\
\hline \multirow{3}{*}{ Temperature } & Hot heat exchangers & $1100 \mathrm{~K}$ \\
\cline { 2 - 3 } & Cold heat exchangers & $400 \mathrm{~K}$ \\
\cline { 2 - 3 } & Loop pipes & $\sim 400 \mathrm{~K}$ \\
\hline \multirow{2}{*}{ Table 1: main values of the Thermo acoustic loop } \\
\hline
\end{tabular}


The MHD generator is used to convert the mechanical energy into electricity. For this purpose the proposed system is based on the oscillation of a liquid metal (sodium is considered the best fluid), imposed by the thermo acoustic effect. The interaction of the fluid oscillation with an imposed DC magnetic field produces an AC electric current circulating in the sodium with the same frequency than the oscillating velocity. This AC current generates itself an AC induced magnetic field, and an AC current in the coil connected with the load. The main elements of the MHD generator are given on figure 2. The oscillating flow (in blue) imposed by thermoacoustic loop, produces AC current in the liquid sodium. The AC current produces AC magnetic field that is transformed by induction process in AC current in a coil connected with the load (Fig. 2)

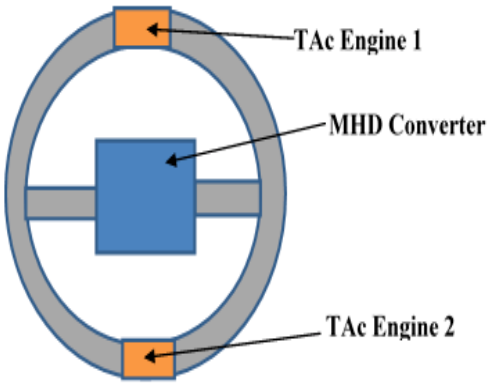

Fig. 1: schematic structure of the thermos acoustic loop

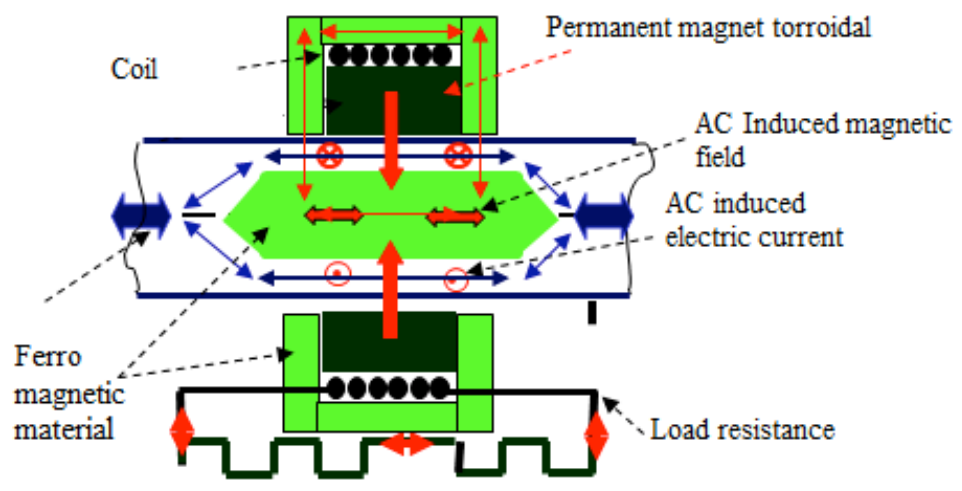

Fig. 2: schematic structure of the MHD generator

The real configuration of the built thermoacoustic prototype is given on figure 3 . The different elements of the loop are represented and the MHD generator (Fig 4) is located in between the two green adaptors.

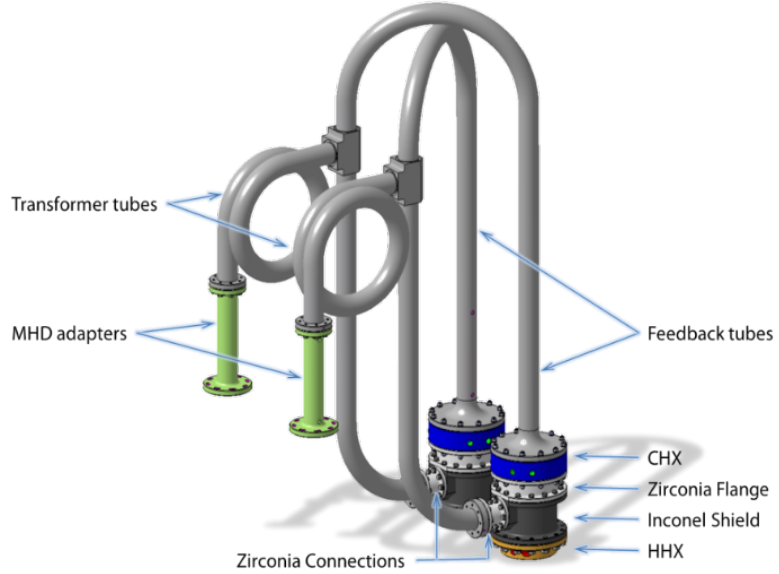

Fig. 3: Main elements of the thermos acoustic loop

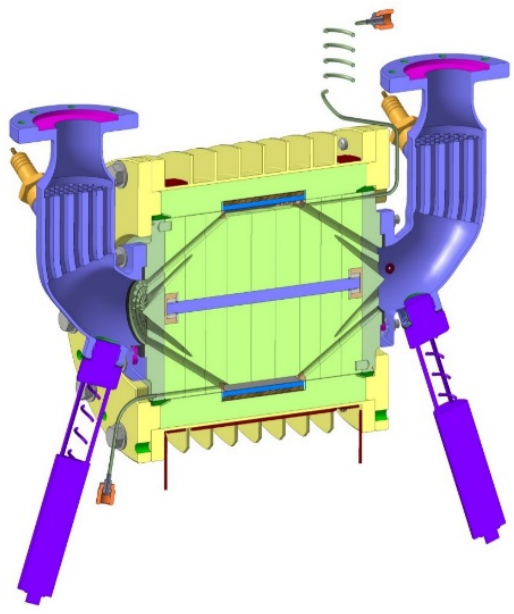

Fig. 4: The MHD generator

First results will be presented at the workshop. The targets below show the expected performances.

\begin{tabular}{|l|l|l|l|l|l|l|}
\hline $\begin{array}{l}\text { Electrical } \\
\text { power }\end{array}$ & $\begin{array}{l}\text { Expected } \\
\text { efficiency }\end{array}$ & $\begin{array}{l}\text { Thermal } \\
\text { power }\end{array}$ & $\begin{array}{l}\text { Temp } \\
\text { Hot source }\end{array}$ & $\begin{array}{l}\text { Temp } \\
\text { Cold source }\end{array}$ & $\begin{array}{l}\text { Carnot } \\
\text { efficiency }\end{array}$ & $\begin{array}{l}\text { Efficiency/ } \\
\text { Carnot efficiency }\end{array}$ \\
\hline $200 \mathrm{~W}$ & $\eta=0.2$ & $1200 \mathrm{~W}$ & $1100 \mathrm{~K}$ & $400 \mathrm{~K}$ & $\eta=60 \%$ & $\eta=0,35$ \\
\hline
\end{tabular}

[1] Réf: The Space TRIPS Project: SPACE THERMOACOUSTIC RADIO-ISOTOPIC POWER SYSTEM: MauriceXavier François, Antoine Alemany, Emmanuel Roy, Janis Friebergs, Gerard Poli, Eleonora Zeminiani, Gunter Gerbeth. 23 $3^{\text {rd }}$ Conference of the Italian Association of Aeronautics and Astronautics. AIDAA2015, Torino,1719 November 2015. 